\title{
Cosmopolitanism with a Twist ${ }^{1}$
}

\author{
Armanda Baruti \\ University of Bern, Switzerland
}

\begin{abstract}
The smaller the world due to mass migration and new technology, the bigger the conflicts due to perceiving ourselves as more different from one-another than ever. There is new hope, however, because cosmopolitanism has made a spectacular comeback to save the day. Unfortunately, everyone seems to be so caught up arguing whether the glass of cosmopolitanism is half full or half empty, that cosmopolitanism is, in fact, causing quite a stir, thus defeating its harmonious purpose. This paper calls for a time-out and proposes a cosmopolitanapproach to cosmopolitanism.
\end{abstract}

\section{Introduction}

Just as a Cosmopolitan cocktail is mistaken for a Martini due to the large cone-shaped glass in which it is served, the concept of cosmopolitanism is often mistaken for an elitist term referring to an impossible social representation characterized by rootlessness and the death of local as well as national identities. However, with the idea of cosmopolitanism being every bit as mouth-watering and refreshing as the cocktail, one cannot help but indulge in it. After all, what intellectual visionary would favour a narrow and local outlook over a more worldly one encompassing global responsibilities? Who would not want to be a citizen of the world? Certainly not Barack Obama, who is one of the first politicians to openly declare the cosmopolitan ideal to be his in a famous speech held on 24 July 2008 where he introduced himself to the Berlin crowd as 'a proud citizen of the United States, and a fellow citizen of the world' (Mieder 2009, p. 121).

Yet, our time is, on one hand, characterized by people's increasing eagerness to define themselves as citizens of the world and a widespread celebration of the melting pot ideal in the form of mixed-race identities, and, on the other hand, by a renewed sense of nationalism, a rising anxiety over immigrants and strengthening of borders. For instance, while a celebrity such as Tiger Woods starring on the Oprah Winfrey show publicly proclaims himself as ‘Cablinasian’, i.e. simultaneously Caucasian, Black, Indian, and Asian, heart-aching reality shows such as U.S. Border Patrol feature on television worldwide how American volunteers, who regard every illegal immigrant as a drug dealer, sabotage water stations set up by humanitarian groups so that the Mexican immigrants trying to cross the border perish of

\footnotetext{
${ }^{1}$ This paper was derived from my MA thesis. 
dehydration. Such inhumane acts lead to a series of questions: why do I have to embrace a special moral responsibility towards other people, for instance towards such destructive vigilante groups vandalizing water stations, for the sole reason that they, by accident, have the same nationality as I? Why should such people be free of any ethical sensibility towards others simply because they happened to be born on the other side of the national fence? As Ulrich Beck points out:

\begin{abstract}
What loses any legitimacy is the fundamentally dubious assumption that such responsibilities are absolute within a border, while their absence is equally absolute outside this border. This exclusion crisis sets off an avalanche of cosmopolitan questions: can the reasons which a society gives for the exclusion of strangers be questioned by members of this society and strangers alike? Who questions, who decides, who justifies and who defines who 'who' is? (Beck 2002, p. 36).
\end{abstract}

The sense of threat felt by many in the U.S. is analogous to that which many Europeans feel pertaining to Islamic immigrants. For instance, in Switzerland, a country which prides itself on being one of the most globalized societies in the world and having cosmopolitan centres such as Zurich and Geneva, a constitutional amendment banning the construction of new minarets was approved in a November 2009 referendum. Is such denial of differences a retreat from cosmopolitanism? Absolutely, according to Stuart Hall, a cultural theorist and sociologist. He sees such policing of boundaries as an attempt to regulate cultural mixing and as a form of cultural fundamentalism, 'a phenomenon by no means only restricted to a certain strand within political Islam' but also 'perfectly compatible with a certain version of western global modernity’ (Werbner 2008, p. 348).

So where exactly does the notion of cosmopolitanism stand with respect to nationalism, multiculturalism, globalization, and so on and what are the reasons for the eagerness of many to embrace it, at least in theory, and of others to retreat from it, at least in practice?

\title{
Defining Cosmopolitanism
}

It has been argued that although cosmopolitanism appears to potentially serve as a thinkoutside-the-box alternative to the nation-state paradigm, the only box it enables us to open is Pandora’s (Poulsen 2008). As Pollock, Bhabha, Breckenridge, and Chakrabarty eloquently put it:

Cosmopolitanism may instead be a project whose conceptual content and pragmatic character are not only as yet unspecified but also must always escape positive and definite specification, precisely because specifying cosmopolitanism positively and definitely is an uncosmopolitan thing to do (Pollock et al. 2000, p. 577). 
However, the claim that engagement in the act of defining cosmopolitanism 'positively and definitely’ may constitute the obstruction of cosmopolitanism itself might just raise reasonable doubt in the mind of a reasonable person. Is there really something inherent in the act of defining that renders it an uncosmopolitan thing to do? In order to answer this question, one not only need to reflect upon whether such a characterization is valid but also reconsider what it means to define.

\section{One Cannot (Not) Define}

Defining cosmopolitanism is an uncosmopolitan thing to do. Defining democracy is an undemocratic thing to do. Really? Shall we define dubiousness then because it seems about the only indubious thing to do? Of course, one could accept the previously mentioned suggestion by Pollock et al. and hastily exclude any definitions as such on grounds of their exclusivistic or 'illiberal' tendencies but would that be more of a cosmopolitan thing to do?

Firstly, the statement above by Pollock et al. seems rather trivial in that 'the positive and definite specification' of any term is an impossible task, in the realm of social sciences at least. This can be exemplified by means of a simple semantics drill involving several people drawing, for instance, a chair and comparing the result with one-another. Although the drawings expectedly vary depending on each individual's perception of a chair based on previous experience with this or that specific chair, and it is impossible to arrive at one single positive and definite design for it, this does not necessarily imply a lack of agreement on what makes a chair a chair, i.e. on chairness so to speak. Secondly, this agreement can certainly be negotiated and altered over time. It goes without saying that the basic definition of a chair cannot and should not make finite a furniture designer's creativity. On the contrary, a proper definition facilitates the familiar, without which novelty and creativity would not exist in the first place. In other words, although a definition of a chair influences the way we think about one, it poses no serious danger as designers and buyers do not build walls around their imagination by restricting it to the conventional model for a chair. Thirdly, there are different approaches to definition. While someone might define a chair by specifying its various parts, e.g. a seat, legs, back, and the material those parts consist of, someone else might take a functional approach to definition by indicating the purpose of a chair, i.e. that it is made for sitting or accommodating a person. While the first consists of countless more product specific, thus ephemeral ideas, the latter constitutes fewer more fundamental, thus longer-lasting and universal ones. However, at some point or another we have all heard of 
how parliament members involved in brawls in countries such as India, Ukraine, South Korea, Taiwan etc., do not only fight for chairs but also with chairs. Needless to say, although, according to the most basic functional definition, a chair is made for sitting, it is ultimately up to individuals to decide what it is used as, whether it be a weapon, ladder, book shelf, footrest and so on. Defining, therefore, entails, to a great extent, an activity of choice.

Clearly, ascribing the label uncosmopolitan to something inevitably implies that there must already exist an idea as to what constitutes the 'cosmopolitan'. The bottom line is that definitions are as impossible as they are inevitable.

\section{A Definition of Definition}

The lay evaluations and stereotypical attitude towards definitions stem from the etymological origins of the term define, which comes from the Latin de finire, literally meaning both to terminate or end and to place within a boundary. Also, the Hebrew word for definition hagdara derives from the same root as the word for fence, gader. Hence, etymologically speaking, it is argued that to define means to establish boundaries, to finish, to locate, to isolate, to distinguish, to differentiate, to set apart, to limit, to dichotomize, etc.

\footnotetext{
A person asked to define his position, in an argument, is being asked to remove ambiguities from a statement of it which, implicitly or explicitly, he is understood to have made, and thus make it clearer and more precise. A photographic image is said to be ill-defined when the degree of blurring is more than can reasonably be permitted. In these ordinary or commonsense uses of the word, it is implied that definition is a matter of degree: to define is not to make absolutely definite what was absolutely indefinite, but to make more definite what was to some extent definite already (Collingwood 2005, p. 94).
}

While, I am inclined to concur with Collingwood's view above that definitions should not be seen as attempting to make definite the indefinite in absolute terms, rather in relative terms, as trying to make more definite the already somewhat definite, I am reluctant to concur with statements such as Oscar Wilde’s famous 'to define is to limit' (quoted in Cauti 2003, p. 200). I choose not to view definitions in this light as I believe that we do not, and should not, limit concepts to their verbal counterparts. To define cannot be equated with to terminate or to end because, after all, it is impossible to 'come to a point at which our knowledge concerning the essence of a concept could be described as complete' (Collingwood 2005, p. 97). Hence, I argue that a different understanding of the word define is required and I define my position by quoting the scholar Brian K. Smith:

To define is not to finish, but to start. To define is not to confine but to create something to refine -and eventually redefine. To define, finally, is not to destroy but to construct for the 
purpose of useful reflection... In fact, we have definitions, hazy and inarticulate as they might be, for every object about which we know something... Let us, then, define our concept of definition as a tentative classification of a phenomenon which allows us to begin an analysis of the phenomenon so defined (Smith 1989, pp. 4-5).

Furthermore, based on the genus - differentia formula handed down to us from Aristotle, a definition is not only based on exclusion but also inclusion, on difference as well as sameness. According to this formula, definitions arise when characteristics perceived as common have been gathered and united into one nature or entity, which constitutes the genus. Then, differentia, i.e. a sort of particularity, is introduced in this perceived homogeneity. For instance, considering rational animal, a classical definition of man based on Aristotle's statement that the human being has a rational principle, animal is the genus and rational is the differentia (Edel 1996, p. 91). Now, should we vilify this definition on grounds that it compels us to decide that humans are different from other animals, label that difference rationality, and conclude that, by definition, humans are rational and all other animals are not? The answer is no. Firstly, such a definition would immediately spark a debate that would hopefully lead to a new definition of man. Whether humans are distinguishable from animals by virtue of their rationality is entirely up for debate. Secondly, one can, in a democratic fashion, take the initiative to propose a different differentia, e.g. rationalizing rather than rational or capable of abstract thinking rather than linguistically capable, etc. Thirdly, instead of taking this definition at face value, deducing that it merely non-innocently dichotomizes rationality vs. animality or culture vs. nature, seeing it as a conspiracy to take whatever we deem as unworthy, in this case irrationality, and project it onto the other, i.e. animals, one is free to just as well focus on its inclusive drive in attributing membership. According to this definition, being human, first and foremost, means belonging to a single community, that of animals, which encloses humans. Thus, depending on how one approaches a definition, it can very well not only presuppose a positive outlook on difference but also a desire to create broad allegiances forming a universal solidarity. Therefore, it is not the act of defining per se which ought to be considered as inherently uncosmopolitan, rather our general attitude towards it as well as the way we might approach and interpret definitions.

Given that a proper definition can promote a deeper understanding, improve communication and lead to a roadmap for further explanation, suggesting that defining is an uncosmopolitan thing to do is, in fact, doing justice to neither the concept of cosmopolitanism nor to that of definition. Is the glass half full or half empty? The choice is ours to make: we can either 
exclude definitions for their alleged exclusivistic or illiberal tendencies or we can include them for their inclusivistic or liberal tendencies.

\section{A Cosmopolitan Approach to Definition}

Instead of conceptualizing a definition as trying to establish firm boundaries from which there is hardly an escape route, we can imagine it as consisting of two levels, the inner of which represents a single community of some agreed-upon fundamental characteristics of what is being defined. For instance, in the case of the chair one such characteristic deriving from its functional definition would be that a chair is intended for sitting. Even the members of parliament mentioned previously, who perhaps envisage a chair to be used for sleeping in, conquering or hitting each-other with, could hardly disagree with this universally acknowledged definition of a chair. The outer level, on the other hand, constitutes a myriad of personal extensions which are much more varied and culturally as well as individually determined. Both of these levels are shaped subjectively and are subject to negotiation and recalibration but whereas the inner level serves as a starting point to establishing understanding, requires a certain amount of consensus and is less disputable, the outer level encompasses each individual's own version rooted in personal perceptions differing from the content of the universally recognized core. This model, thus, proposes constructing and perceiving definitions as composed of two layers, i.e. what is common and what is particular, convergence and divergence, sameness and difference, unity and diversity, the global and the local. Hence, contrary to the suggestion made by Pollock et al., definitions seen in this light reflect the core principle of cosmopolitanism, which is suggested in the following sections.

\section{A Cosmopolitan Approach to Cosmopolitanism}

In this section I dare take the risk of being charged with first-degree non-conformity to cosmopolitanism itself and endeavour to pin down its meaning, although the task is as simple as nailing the frothy bright pink concoction of vodka, triple sec, lime juice and a dash of cranberry to the wall. Before applying the previously proposed cosmopolitan approach to defining cosmopolitanism, the attention is turned to the nature of cosmos and polis as this might prove fundamental for a better conception of cosmopolitanism.

\section{The Cosmos and the Polis}

Of course, we all know how the luxury vacation ends for the girls that made popular the Cosmopolitan cocktail: In Sex and the City 2, Samantha has trouble controlling her urges and 
is arrested for kissing someone in public in Abu Dhabi, in the movie at least; in reality the scenes were shot in Morocco because the government authorities in both Dubai and Abu Dhabi declined the request for filming based on moral objections to the film's name.

While much of human conduct is not regulated by law, public love-making undoubtedly is, not only in Abu Dhabi but in most contemporary cities and towns around the world. The prosecution of indecent public behaviour dates back to antiquity. The ancient Athenian society, for example, operated based on the politics of reputation, i.e. honour vs. shame, the politics of gender, i.e. male vs. female and the politics of spatial differentiation, i.e. public vs. private (Cohen 1991). Non-conformity to Athenian customs meant living life with shame and dishonour, which was commonly regarded as a fate worse than death - but it also meant living life as a citizen of the universe, i.e. as a kosmopolite. The word derives from the Greek cosmos (Kó $\sigma \mu \mathrm{o} \varsigma)$ denoting the universe and polis (Пó $\lambda \mathrm{s} \varsigma)$ the city. Such a kosmopolite was a woman named Hipparchia. She was an ancient female Greek philosopher who lived by the Cynic principle of parakrattein to nomismata, meaning to deface the currency. To deface in this metaphorical motto signifies changing the false values of the dominant culture, i.e. ‘driving out the counterfeit coin of conventional wisdom' (Branham and Goulet-Cazé 1996, p. 8). Initially adopted by Diogenes of Sinope, the man credited with the first known use of the word cosmopolitan, this Cynic principle of defacing the currency implied rejection of the prevailing social and political order in favour of an unconventional, self-sufficient life as a kosmopolite. Hipparchia fell in deeply love with Crates, a Cynic philosopher who had been a student of Diogenes of Sinope.

Diogenes preached "cosmopolitanism," declaring himself "without a city” (a-polis), "without a home" (a-oikos), and "citizen of the universe" (kosmopolites)... Diogenes urged people to abstain from all political engagement that, like family or social obligations, might constitute an obstacle to individual freedom (Branham and Goulet-Cazé 1996, p. 24).

Hipparchia faced her parents' objections by threatening to kill herself if she was not allowed to marry Crates. She changed the currency, thereby becoming a cosmopolite, by rejecting conventional materialism, embracing self-sufficiency and mental asperity. Most of our knowledge about Hipparchia and other Cynic philosophers comes from anecdotes and sayings reported by later authors such as Diogenes Laërtius and later Christian writers.

Hipparchia was the first known woman Cynic. Choosing the manly life of the Cynic meant not only rejecting social institutions but also choosing hardship and poverty over material comfort. Cynics strived to live according to nature by rejecting artificial social conventions 
and refusing all luxuries and any items not absolutely necessary for survival. They gave up their possessions, only wore a simple mantle, and begged on the streets. Furthermore, while women of Hipparchia's social class were expected to be weaving and organizing the household servants, she defended the legitimacy of her presence at Greek symposiums traditionally attended only by men when this legitimacy was disparaged by other philosophers. Wearing the same mantle as Crates, typically male clothing, Hipparchia appeared with him in public everywhere, thus defying the tradition of keeping women sequestered at home. She upheld the Cynic value of anaideia, or shamelessness. She and Crates supposedly consummated their marriage by having sex on a public porch in broad daylight. Crates' decision to marry is quite odd as marriage was a social institution of the sort normally rejected by Cynics. Earlier Cynics like Diogenes of Sinope had maintained that the philosopher would never marry. Crates is said to have called their marriage a cynogamy, meaning dog-coupling. In fact, the word Cynic itself derives from the Greek word kuon, or dog. This is why philosophers like Diogenes of Sinope, Crates and Hipparchia are also known as the Dog Philosophers. Aristotle, a contemporary of Diogenes, justified the label as follows:

\footnotetext{
There are four reasons why the Cynics are so named. First because of the indifference of their way of life, for they make a cult of indifference and, like dogs, eat and make love in public, go barefoot, and sleep in tubs and at crossroads. The second reason is that the dog is a shameless animal, and they make a cult of shamelessness, not as being beneath modesty, but as superior to it. The third reason is that the dog is a good guard, and they guard the tenets of their philosophy. The fourth reason is that the dog is a discriminating animal which can distinguish between its friends and enemies. So do they recognize as friends those who are suited to philosophy, and receive them kindly, while those unfitted they drive away, like dogs, by barking at them (quoted in Navia 1996, p. 94).
}

These philosophers obviously embraced this name designation as well as what it represented. Their willingness to accept this derogative term confirms that they upheld animals as models of life according to nature. The Cynics adopted unconventional positions also in religious terms. By living like dogs and following their natural inclinations so as to get in tune with the natural world order, they changed the status quo hierarchy animal-human-god to humananimal-god. The human constituted the concrete model, whereas animal and god 'the theoretical model of self-sufficiency and indifference, and consequently of happiness' (Branham and Goulet-Cazé 1996, p. 24). This, however, did not mean that the Cynics were religious. In fact, they envied animals for not living in constant fear of the gods. Diogenes also defaced philosophy in that, not only did he prefer to live out his philosophical beliefs, 
unlike other philosophers he criticized, but also in that he regarded philosophy outside our grasp.

Just as Crates was influenced by his teacher Diogenes of Sinope, Hipparchia and Crates influenced their pupil Zeno of Citium, the founder of Stoicism in the early 3rd century BC. Zeno allowed the quenching of sexual desires even in public and advocated the equality of the genders, coeducational public exercise, and living according to nature in the sense of conforming one's own reason to the dictates of the rational natural law. According to Stoic cosmopolitanism, all people are manifestations of the one universal spirit, ought to live in brotherly love and readily help one another. The Stoic philosophy was geared towards helping anyone in need, regardless of gender, ethnicity, religion, and social status.

What truly made the Stoic idea of offering help to any fellow human in need revolutionary was the fact that this help was extended to slaves, many of whom were brought in from conquests abroad. Even though in its early stages Stoic cosmopolitanism was chiefly a moral cosmopolitanism, political aspects still figured in as cosmopolitanism faced, right from the start, the conflict between idealism vs. pragmatism. Morality vs. the political practicality one of the main problems surrounding contemporary notions of cosmopolitanism - was present right from the infancy of cosmopolitanism. Is loyalty and the feeling of mutual affinity greater within one's own family, city, country than the loyalty to the world at large? Should help be offered by providing hospitality at home or by going abroad? Who is eligible for receiving help?

The cosmopolitanism of the Stoics, which has been relayed and defended by Martha Nussbaum (1994) as a stance she urges we should adopt today, can be explicated by means of two metaphors put forth by Nussbaum. The first comes from the Roman Emperor Marcus Aurelius and involves a visualization of the entire world of human beings as the limbs of a collective humanity, and the second a picture of human interaction as a series of concentric circles. Although useful in facilitating imagination, both of these metaphors should raise some eyebrows. Conceiving of the entire world of human beings as one collective body and of people as its many limbs, would almost certainly lead to a conceptualization of certain individuals or groups as a cancer to this body of a collective humanity. Furthermore, the image of a series of concentric circles is also flawed. As Nussbaum relays, the circles represent the Stoic idea that one can be a citizen of the world without giving up local identifications and that instead of thinking of ourselves as devoid of local attachments, we 
should think of ourselves as surrounded by a series of concentric circles and part of a greater whole. The individual draws the first circle around the self; the next around one's immediate family; followed by the extended family; then one's neighbours or local group, one's fellow city-dwellers, one's fellow countrymen and so on. The largest and outermost of all these circles is that of humanity as a whole. The citizens of the world must use reason to 'draw the circles somehow toward the centre', thus making all human beings more like their city codwellers, connecting and harmonizing themselves with the ethics of all humanity (Hierocles quoted in Nussbaum 1994, p. 4). However, what if others do not wish to be made like our city co-dwellers? Besides, such a model of solidarity circles radiating outwards from the centre and becoming fainter with distance implies that humans feel stronger attachments to narrower circles, which must not necessarily be the case. The majority of Americans, for instance, would probably identify much more with the nation than any particular state. Likewise, there are also plenty of Swiss who feel greater solidarity with the nation of Switzerland rather than the particular canton they live in.

Augustine of Hippo, a Latin-speaking philosopher very influential in the development of Western Christianity, took up Stoic cosmopolitanism but with a twist. The Christian cosmopolis was a community strictly for those who shared the belief in a Christian God. Christian cosmopolitanism, as such, was an exclusivist cosmopolitanism, if that is not too much of an oxymoron. Obviously, from its earliest beginnings, cosmopolitanism was confronted with one fundamental question: Can cosmopolitanism be extended so as to accommodate others who do not subscribe to its beliefs, whether they be Roman, Christian or Stoic?

After having looked at the roots of the concept in ancient Greek thinking, some traces of which are still with us today, the attention is turned to cosmopolitanism as it was reinvented within the political philosophy of the Enlightenment, in particular the Kantian sense of cosmopolitanism which has had an enormous impact on the debate to date. According to Immanuel Kant, an 18th-century German philosopher, the natural state of humans is that of dog eat dog, of a war of all against all and it is man's telos to free himself from this state of war. His Idea for a Universal History from a Cosmopolitan Point of View and Perpetual Peace basically represent an outline for the fulfilment of this telos and the realization of human perfection. Kant's writings for a peaceful coexistence of human beings emerge from a period of a heavily war-torn Europe. To contextualize his writing one must keep in mind the (at that time) recent French Revolution, which Kant abhorred. Quite interestingly, in the 
introductory paragraph of his 1795 essay entitled Perpetual Peace, a paragraph which could be described as a prophylactic disclaimer to protect himself from possible malevolent interpretations and backlash by the very statesmen under whose protection is writing, Kant assures that politicians must not fear his ideas and consequently demands of them to let him be:

The practical politician assumes the attitude of looking down with great self-satisfaction on the political theorist as a pedant whose empty ideas in no way threaten the security of the state, inasmuch as the state must proceed on empirical principles; so the theorist is allowed to play his game without interference from the world-wise statesman (Kant 2007, p. 5).

Furthermore, what makes this clausula salvatoria striking is the way Kant takes up the dichotomy between idealist and realist political philosophies by pitching the philosopher against the politician. This dichotomy, in turn, has perpetually become the centre of controversy revolving around the debate on cosmopolitanism between realist and idealist political philosophers. Kant’s apparent assertion that philosophical ideas exist so as to transcend the purely practical political concerns comes with a but:

But if, in consequence of enlightened concepts of statecraft, the glory of the state is placed in its continual aggrandizement by whatever means, my conclusion will appear merely academic and pedantic (Kant 2007, p. 5).

Kant bases his attempt to transcend the nation state on the uncommon assumption that the same rights that can be claimed by single individuals can also be claimed by nation states. The Golden Rule echoed in Kant's essay forbids treating a human being as a means to an end because a rational human being is always an end in her/himself. It is along these lines that Kant argues that no nation state is allowed to simply take possession of another. This raises a question which plagues Kant's entire essay, namely whether the analogy comparing nation states to reasonable beings themselves can be said to hold. One problem associated with this analogy is that one can politely or impolitely ask an individual to remove her/himself from the neighbourhood; a nation state, however, cannot do so, even though, according to Kant, every state as every individual is forced to expect the worst from the other. Kant lists a series of preconditions that must be satisfied, if perpetual peace is ever to exist. He puts forward the idea of acknowledging the absolute sovereignty of states and disapproves of all standing armies for having war as a purpose and for resulting in national debt, which, in turn, might serve as a pretext for further wars. 
In Perpetual Peace Kant stages a cosmopolitan right as a guiding principle to protect people from war, and morally bases this cosmopolitan right on the principle of universal hospitality - thereby basically setting the ground for present-day asylum seekers. For Kant, if foreigners act in a peaceful manner, they are entitled the right to hospitality in a foreign country. In his own words:

\begin{abstract}
Hospitality means the right of a stranger not to be treated as an enemy when he arrives in the land of another. One may refuse to receive him when this can be done without causing his destruction; but, so long as he peacefully occupies his place, one may not treat him with hostility. It is not the right to be a permanent visitor that one may demand. A special beneficent agreement would be needed in order to give an outsider a right to become a fellow inhabitant for a certain length of time. It is only a right of temporary sojourn, a right to associate, which all men have. They have it by virtue of their common possession of the surface of the earth, where, as a globe, they cannot infinitely disperse and hence must finally tolerate the presence of each other. Originally, no one had more right than another to a particular part of the earth (Kant 2007, p. 21).
\end{abstract}

Kant's hospitality grants a stranger the right to temporarily stay within a certain territory without, however, enjoying the same rights that its citizens do. Apart from its communist overtone, the 'common possession of the surface of the earth' is also reminiscent of the Stoics.

Kant compares nation states to savages subject to an existence characterized by senseless and lawless freedom. This, he argues, is a state that can be overcome by pursuing a more rational and regulated freedom through the establishment of a League of Nations. In his 1784 essay translated to English as Idea for a Universal History from a Cosmopolitan Point of View, Kant presents history as gradually progressing towards a particular end point, i.e. towards a state of human perfection. This end of the road perfect state for Kant is cosmopolitanism, the League of Nations, the fulfilment of humanity's telos. Humanity progresses towards this point as a result of sheer necessity and antagonism. By antagonism Kant means, 'the unsocial sociability of men, i.e., their propensity to enter into society, bound together with a mutual opposition which constantly threatens to break up the society’ (Kant 1963, p. 15). Nations, according to Kant, driven by necessity and antagonisms, will progress towards 'a distant international government' whose end point is a 'universal cosmopolitan condition' (Kant 1963, p. 23). He himself, however, admits 'that with such an Idea' structuring his master narrative ‘only a romance could be written’ (Kant 1963, p. 24).

Kant's view of a teleologically unfolding history moving towards cosmopolitanism not only suggests that even for Kant cosmopolitanism constitutes a millennial concept but also begs 
the question: without any further obstacles and antagonisms to overcome, will humanity simply become slothful? Kant's cosmopolitan (hi)story can be seen as an endeavour on his part to fulfil a sort of romantic longing by bringing sense to a seemingly senseless history.

Despite the attractiveness of 18th century cosmopolitan ideals, nationalism and internationalism became the dominant ideas in the modern world and cosmopolitanism came to be associated with those who were stateless or not committed to the national project, e.g. the Jews and the aristocracy, respectively. However, prompted by a growing awareness of globalization, cosmopolitanism has once again stolen the spotlight and Kant’s political writings serve as the main source of inspiration for contemporary cosmopolitan theory.

\section{The General: A Contemporary Blueprint}

While we would agree that the shameless actions of the self-proclaimed Hellenistic cosmopolites would probably, even from our contemporary perspective, constitute public indecency, we are aware that no definition of public indecency covers all the possible circumstances that such a term might cover. Lawmakers, for example, cannot be expected to be able to foresee all the ways in which it is possible to commit public indecency. Courts of law continuously refine the meaning of the term as new cases occur; they diminish the vagueness and their decisions become precedents for future reference. Even established terms need improving and refining and perhaps even reinventing. What makes cosmopolitanism such a term in desperate need of refinement is especially suggestions like the one below by Pollock, Bhabha, Breckenridge, and Chakrabarty:

[W]e already are and have always been cosmopolitan, though we may not always have known it. Cosmopolitanism is not just—or perhaps not at all—an idea. Cosmopolitanism is infinite ways of being (Pollock et al. 2000, p. 588).

This seems like a philosophical dead-end: A tree falls in the forest; no one is there to hear it; does it make a sound? Likewise, someone is cosmopolitan by default; they do not know they are; are they cosmopolitan? Would it not make more sense to conceptualize cosmopolitanism as performative, i.e. in terms of ways of doing, rather than ways of being? Cosmopolitan is not something one is, rather something one does. How exactly can one do cosmopolitanism? While it is impossible to foresee all the ways in which it is possible to do cosmopolitanism, one fundamental way that has stood the test of time certainly seems to involve defacing the currency, i.e. defying what is taken for granted. In the vein of Cynic philosophy, defacing the currency was an individual attitude and discipline. As Martha Nussbaum points out: 
Becoming a citizen of the world is often a lonely business. It is, in effect, as Diogenes said, a kind of exile - from the comfort of local truths, from the warm nestling feeling of patriotism, from the absorbing drama of pride in oneself and one's own (Nussbaum 1994, p. 6).

This may still hold true in a present-day world in which cosmopolitanism stands for political protest rather than individual lifestyle. Incorporating cosmopolitan perspectives into national and local political affairs does seem, as a matter of fact, to be a lonely business. In Ronald Stade’s words:

\footnotetext{
Fighting for a global constitution and rule of law, to many may appear as tilting at windmills. Here, however, we can learn from Diogenes of Sinope, Crates and Hipparchia, and all the other shameless Dogs. Although cosmopolitanism no longer is about personal salvation or becoming godlike, it continues to defy much of what is taken for granted. It is still about parakratein to nomismata, “defacing the currency” (Stade 2007, p. 12).
}

This defacing of the currency can occur across various dimensions of cosmopolitanism, i.e. political, cultural, and moral. For example, Chris Brown, an international relations theorist, defines cosmopolitanism along its political dimension as 'the refusal to regard existing political structures as the source of ultimate value' (1992, p. 24). This definition has become wider for many so as to encompass open-ended trans-national and supranational projects as well as seeking a trans-ethnic community within the boundaries of a particular nation state. In the contemporary context and along its cultural dimension, as Waldron underlines, cosmopolitanism means:

[T] he ability to stand outside of having one's life written and scripted by any one community, whether that is a community of faith or tradition or religion or culture ... and draw selectively on a variety of meanings (quoted in Vertovec and Cohen 2002, p. 4).

Alternatively, cultural cosmopolitanism has been said to emphasize 'the value of global cultural pluralism’ (Kleingeld 1999, p. 506). While Waldron seems to make a valid point, Kleingeld's view appears somewhat muddied as cultural pluralism can be differentiated from cosmopolitanism. This distinction is made in a subsequent section of the paper. Finally, along the moral dimension, cosmopolitanism is generally grounded in characteristics universally shared among humans (and sometimes other kinds of beings). For Aristotle in 350 BC this shared characteristic was a telos (Edel 1996, p. 62), for Kant in 1795 it was reason (Kant 2007, p. 45), for Bentham in 1780 it was the capability to suffer (Bentham 2008, p. 20). Lévinas in 1961, on the other hand, based his ethics not on what humans share, rather on otherness (Lévinas 1991, pg. 16). The previously mentioned notion of hospitality put forth by Kant can serve as an example of 'an obligation established by universal human reason which 
is morally legislative' (Kant 2007, p. 45). Every stranger, he argues, has the cosmopolitan right not to be treated as an enemy upon arrival in the land of another (Kant 2007, p. 21). Providing this hospitality constitutes a moral obligation.

Contemporary cosmopolitanism seems to have been turned into a collective ethical as well as institutional project. The changes of the last two millennia have enabled cosmopolitanism to shift from the private to the public sphere, i.e. from individual struggle to institutional configuration. Such institutions designed to embody the ideal of cosmopolitanism can be exemplified by: the humanitarian institution of the International Committee of the Red Cross founded in 1863 to protect human life and health and alleviate human suffering without discrimination based on nationality, race, gender, class, etc.; the International Criminal Police Organization established in 1923 to ensure public safety, fight terrorism, crimes against humanity, environmental crimes, etc; the World Bank established in 1944 to provide lowinterest, interest-free loans, and grants to developing countries in an aim to reduce poverty; the League of Nations which was created in 1919 to maintain world peace and was eventually replaced by the United Nations after the end of World War II in 1945; the North Atlantic Treaty Organization founded in 1949 and committed to a strong and productive cooperation with the UN; the European Union, an economic and political union of sovereign nation states also established in the aftermath of World War II known to operate through supranational independent institutions; and even the fictional United Federation of Planets in Star Trek apparently upholding the values of universal liberty, equality, justice, cooperation, and peace. If the abolition of war is a prerequisite for a peaceful co-existence, should this prerequisite be fulfilled by establishing a single universal authority such as an all-powerful United Nations or by abolishing nation states altogether since it is nations that wage wars against one-another? In the vein of Kantian cosmopolitanism, if there ever will exist a cosmopolis, which institutional state form will it take and will the nation be left behind?

Not necessarily. In view of contemporary cosmopolitan theory, cosmopolitanism does not mean that the nation is no longer a politically relevant community. Delanty argues that 'cosmopolitan refers to the end of the "closed society" of the nation-state, but does not spell the end of the nation' (2008, p. 220). The post-universal cosmopolitanism that he proposes 'is critical and dialogic, seeing as the goal alternative readings of history and the recognition of plurality rather than the creation of a universal order, such as a cosmopolis' (Delanty 2006, p. 35). Quite interestingly, even contemporary notions of cosmopolitanism bear resemblance to 
the Cynic philosophy of defacing the currency. Delanty not only argues, for example, that 'cosmopolitanism must be seen as one of the major expressions of the tendency in modernity towards self-problematization,' but also endeavours to defy some usually taken for granted pitfalls of cosmopolitanism such as Eurocentrism, universalism and relativism (2006, p. 35). It is precisely this 'condition of self-problematization' and 'self-scrutinization' that, in his view, characterizes ‘the cosmopolitan imagination’ (2006, p. 25). Therefore, along these lines, cosmopolitanism in practice involves not only defacing the currency, i.e. rejecting the dominant status quo, but also defacing one’s own currency as well as its own currency, i.e. the currency of the self and of itself.

Clearly, whether the discussion is anchored in individual approaches or around institutional implications, the principle of defacing the currency, implying a rejection of the prevailing status quo in favour of a new cosmopolitan vision, seems to underlie every dimension of cosmopolitanism.

\section{The Particular: Personal Extensions}

Much to the dismay of Toby Cecchini’s (2004), who standardized the method for preparing the Cosmopolitan using Cointreau and freshly-squeezed lime juice, there are as many versions of the cocktail as there exist bartenders in the world. Similarly, there might be as many cosmopolitanisms as there are individuals claiming cosmopolitanism. Each flavour of the notion is rooted in each person's own local discourse.

My personal concoction includes a willingness to educate and commit myself to global issues such as the environment, a feeling of being at ease with more than one cultural setting, not so much the willingness to listen to the voice of experience, rather to have the courage to be the voice of experience myself. Another key ingredient is the flexibility in appropriating cultural forms or practices from elsewhere without the fear of this jeopardizing my identity.

Cosmopolitanism in practice, the way I understand it, does not involve loudly proclaiming oneself as a proud teenage lesbian or as a proud Kosovo Albanian or as a British celebrating a Swedish sofa or even as a cosmopolitan. Rather, cosmopolitanism can be conceptualized as a kind of performative practice through which one (as well as cosmopolitanism itself) avoids being branded. It involves resisting the notion that one’s identity is determined by brands. However, considering that 'we live in a society where youth recognize 1,000 corporate logos 
and fewer than 10 species of wildlife found in their communities' (Bateman 2008), even this notion of cosmopolitanism seems overly optimistic.

The most important ingredient in my cosmopolitan concoction is love. However, this love does not only extend to my fellow human co-dwellers in the world as Martha Nussbaum (1994) suggests but also to all other living creatures. Moreover, doing cosmopolitanism means being as loyal to any nation as I am to any brand. In tune with the marketing saying, 'there are no more customers, only prospects' (quoted in Kataras 2008, p. 35), I consider myself a prospect rather than a citizen of any country. Nevertheless, I try to remain attentive to the social conditions and the situations of those who do not share my privileges of transcending national identities.

Cosmopolitanism has meaning beyond the weakly translated world-citizenship and that a theory enabling a deep conception of the cosmos, polis and their harmonization has yet to come. In the meantime, cosmopolitanism, nonetheless, encourages us to rethink the relation between the self, community, and the world. It is important for us to think about how we concoct our cosmopolitanisms and what we do with them so that we can do cosmopolitanism not only intuitively as suggested by Pollock et al. but also by conscious commitment.

\section{Mutual Affinity}

Cosmopolitanism, as it is widely understood today, contends that solidarities among people should be built based on a shared humanity. Cosmopolitanism is often equated to universalism, which is also potentially global or transnational in scope. In universalist terms people are united by virtue of a common adherence to a set of universally applicable ideals such as a liberal democratic creed, religion, etc., regardless of national or cultural divides. These ideas and values are, thus, capable of transcending territorial or cultural boundaries. Universalist solidarity is grounded on a shared ideology and extends to anyone who commits and shows loyalty to the ideology. An example would be the world-wide coalition against a common enemy such as Al-Qaeda. Universalists, however, differ from cosmopolitans in that cosmopolitans do not require others to identify with a particular set of ideas, such as political beliefs and cultural values, as a precondition for mutual affinity. The line is still somewhat blurry though because humanity is itself an idea, but cosmopolitanism, even more so than universalism, values cultural diversity as a defining trait of humanity and is more insistent on preserving that diversity. From a cosmopolitan point of view, unity is not the same as 
uniformity and diversity is not the problem, rather the solution. Diversity in sameness is the tenet of the European Union. For universalists, on the other hand, a common identity requires a common and homogeneous worldview. An argument made against universalism by postmodern scholars such as Jennifer Hochschild (1984) is that when it comes to shared ideologies, the global is too global, i.e. no creed is universalizable, although we would like to think otherwise. Values and ideas are at least partially predicated on the culture and linguistic tradition from within which they originate. Universalism is not only believed by many to be practically impossible but also undesirable.

Coexistent with cosmopolitanism, hardly the dominant conception of belonging, and universalism, which extends solidarity to anyone adhering to a common set of ideas, are at least two other popular traditions, namely nationalism and multiculturalism. Nationalism identifies the members of a nation as a united and distinct people and restricts solidarity to that narrow circle. As defined by Anthony Smith, the 'core doctrine' of nationalism maintains that 'the world is divided into nations, each with its own character, history and destiny' (2004, p. 245) and that 'an individual's primary loyalty must be to her or his nation' (1991, p. 74). Nationalism is considered dangerous because it heavily relies on the principle of exclusion. National solidarity is the public spirit that stops at the national borders, i.e. a feeling of mutual affinity that binds all the fellow citizens of a nation but does not extend to other nations. This solidarity is grounded in a common national identity built around soperceived exceptional characteristics or shared particularities which are associated with the whole nation, used to characterize it, to distinguish and separate it from other nations. In other words, these exceptional characteristics are shared by the members of a nation alone. These shared characteristics are perceived to involve race, religious heritage, language, national history, cultural symbols and traditions, a set of political institutions and so on. As Smith points out, however, a nation's distinguishing characteristics that unite all its members while simultaneously severing them from non-members boil down to the 'common myths and memories,' the 'distinctive public culture,' the 'historic homeland,' the 'common laws and customs.' In his own words, the nation is:

a named and self-defined community whose members cultivate common myths, memories, symbols and values, possess and disseminate a distinctive public culture, reside in and identify with a historic homeland, and create and disseminate common laws and shared customs (2005, p. 98). 
Nationalism, thus, contends that the members of a nation share important characteristics which can serve as a basis for solidarity limited by territorial boundaries as well as ethnocultural divisions. This is in contrast to the multi-culturalist or the culturally pluralist tradition which dismisses national identities as not only artificial but also spiritually meaningless. This tradition favours more localized and narrower attachments such as regional or state communities, particular interest groups and so on. Pluralism characterizes the nation as a disunited mishmash and, to a certain extent, it ignores the tensions that arise and denies the need for solidarity altogether, i.e. multiple cultures can coexist without blending. The majority of cultural pluralists believe in the coexistence of multiple groups under the same political roof, without the need for a strong common bond. Underlying pluralism is the notion that we can only feel attachment to a part of the whole, rather than the whole itself. One important implication is that it is not particularity per se, rather one's status as a marginalized minority that moves to the foreground. For instance, Judith Butler is a lesbian rather than Jewish; Barack Obama is black, not Christian; we are aware of Hillary Clinton’s gender.

There has been a rather recent wave of right-wing conservative nationalism in Switzerland, which arose in part in response to the popularity of multi-culturalism and interest-group liberalism, which is perceived to pose a threat to national unity. For the Swiss, posters such as the following distributed by SVP, the Swiss People's Party, have become all too familiar:




The figure illustrates some of the billboards mushrooming all over Switzerland in recent years. They are propagated by the SVP, known for its adherence to national conservatism, its commitment to reducing immigration inflow, rejection of increases in government spending on social welfare and education, its opposition to closer ties with the NATO and to increased involvement of Switzerland in supranational organizations such as the UN, EU, etc. The posters portray Switzerland as being pierced by minarets which look like missiles; a flag being stepped on by the black feet of immigrant masses; a tiny Switzerland being chewed up by big, black crows; many coloured hands each trying to grab a Swiss passport, and, of course, the black sheep being kicked out by the white ones. Each poster, as fear-instilling and discriminatory as it might seem, is actually associated with the proposal of a new law. For example, as mentioned in the introduction to this paper, in November of 2009, in an act of direct democracy, a ban on the construction of minarets, proposed by SVP members, was approved by the majority of voters (57.5\%) and became an amendment to the Swiss Constitution.

A multi-lingual and multi-ethnic country such as Switzerland, where the World Economic Forum takes place and where a number of international organizations are headquartered due to the fact that it is considered a so-called neutral country, seems anything but neutral in light of such images.

Cosmopolitan solidarity is advantageous, in that it attempts to reconcile the dilemma between the inevitable presence of social diversity and the sense of homogeneity necessary for societies to remain united and free. Cosmopolitanism does not deny diversity, rather affirms it. Clearly, although conservative nationalists may argue otherwise, no nation has ever been homogeneous. Multi-culturalism and pluralism may be new words but not new trends. All nations put under the test of distinct national character would most probably fall through due to a lack of homogeneity necessary to unite them, whether this homogeneity be territorial, linguistic, cultural, political or religious. Cosmopolitan solidarity, thus, appeals to a category which is higher, more abstract, idealistic and broad so as to encompass all humans. Cosmopolitanism provides a sense of universal human solidarity as a direct consequence of diversity rather than in spite of it. If we accept the premise that a community cannot survive free and independent unless its members feel some attachment to the whole, then cosmopolitanism seems to make more sense than pluralism, which promotes narrow factional interests and separate cultural traditions. Even if we accept the apparent inescapability of 
pluralism, the extent to which we define ourselves in opposition to the whole based our distinctive characteristics, this does not rule out the possibility of a shared human identity. Humanity can still be conceived of as distinct within a larger universal collective or whole of creatures and beings, i.e. that which is human as opposed to that which is not.

\section{Ethnogamy: It Is All in the Mix}

'Like any shaken drink, the Cosmopolitan wants to be brutalized. There should be aeration, collision and dilution galore going on in that shaker,' says Toby Cecchini, the New York bartender (2008). One takes a sip and surprise, surprise, the ingredient of individuality is not lost, rather strengthened! One can still taste the triple sec made from sun-dried peels of bitter Caribbean oranges. That tiny dash of cranberry now sweeps over the tongue like a giant wave of freshness. Would lime juice even taste as good, if it were not fused in this particular citrusy sweet mixture?

Cultures too, are fluids that are inevitably mixed. Culture is a fluid process. As Delanty points out:

It is possible to see cosmopolitanism expressed in the mixing and re-packaging of cultures and identities. This might be a weak expression of cosmopolitanism but, depending on the degree of self-transformation that results, it may also take a stronger form (2008, pp. 219-220).

Short or long? Weak or strong? The quick fix is all in the mix! Toby Cecchini could have told us that much.

Obviously, thinking of culture in a nationalist framework is absurd because culture has always been fluctuating. There exists no single authentic culture. Even Native American jewellery, which is commonly perceived as authentic, for instance, was heavily influenced by Spanish jewellery. Cultures have always been cross-fertilized and influenced by others. Of course, it may be hard for some people to accept that another culture has fertilized theirs because they can then no longer claim superiority over the other culture, if they indebt their own culture to the other. For this reason, colonizers could not admit that the colonized countries had fertilized their own culture. They projected upon the colonized what was other in themselves, while denying any sameness that the colonized shared with them.

Given the heightened awareness that it is only one's projection onto the Other that makes it other than oneself, forming our cultural identities by excluding what we are not because the rest constitutes what we are seems like an ultimately unrewarding form of imprisonment. 
Thus, it becomes increasingly difficult to buy into the argument that solidarity requires an Other, an excluded them against whom we can define us and that 'collective identities can only be established on the mode of an us/them' (Mouffe 2000, p. 13).

Cosmopolitanism involves defining oneself with another, not against another. In doing so, we can reach a far more profound sense of definition as expression of meaning. We must define ourselves and our cultures not based on negation and mutual exclusion but through affirmation and mutual recognition, i.e. as contained in one-another. Since cultures are dependent on one-another, we have the makings of a marriage. Hence, instead of viewing cultures, in a romanticized nationalist light, as distinct from one another, I propose the term ethnogamy to denote the process by which contemporary cultures become cosmopolitan. Ethnogamy stems from the union of the Greek ethnos ( $\varepsilon$ $\theta v o \varsigma)$, meaning nation or cultural group, and gamos ( $\gamma \alpha \alpha_{\mu} \varsigma \varsigma$ ), meaning marriage or union. We should by all means not limit this union to only two cultures. However, Ulrich Beck's description is useful in triggering the imagination as to when a couple is considered a couple:

The French sociologist Jean-Claude Kaufmann (1994) has a very sophisticated answer: a couple is not formed when two people start living together, or when they start having sex. Something else must be added: a couple begins when two persons buy one washing machine not two! Why? Because then the quarrels about 'Dirty Laundry' (the title of his marvelous book) start. Who washes for whom? What counts as dirty? What as clean? What happens in each case, if he says yes and she says no? (Beck 2002, p. 25).

Ethnogamy emphasizes the fundamental need for unity, collective decision-making and reflection on a shared collective future. Multi-culturalism, the extent to which we define ourselves in opposition to the whole, on the basis of our distinctive traits, poses a serious challenge to the very notion of cosmopolitanism itself, which demands solidarity and bonding. This feeling of cosmopolitan mutual affinity can better be established by allowing newcomers to mix their own cultural practices into the melting pot, rather than requiring a complete assimilation on their part into the pre-existing host culture, i.e. integration by means of eliminating difference. Like a good Cosmopolitan cocktail, the multi-ethnic melting pot needs to be shaken and brutalized until it takes the form of an ethnogamy.

\section{Cosmopoliteness}

Politeness lies within the same semantic field as cosmopolitanism. Politeness stems from the Latin polìre (to polish) and means polishedness, which refers to another word in this semantic field, urbanity. In Latin the word originally referred to a mentality and a behaviour which one 
ought to have in the urbs (the city) of ancient Rome. The fact that, in just three steps, almost any dictionary will take one from polite to urbane to cosmopolitan speaks to the relatedness of these notions.

Politeness as a facilitator of sociability is an essential aspect of public and private everyday culture, of business and of diplomacy. Kant's roadmap to cosmopolitanism involves transcending antagonisms among individuals and nation states alike. He refers to these antagonisms as 'the unsocial sociability of men, i.e., their propensity to enter into society, bound together with a mutual opposition which constantly threatens to break up the society' (Kant 1963, p. 15). Since social sociability seems to be a fundamental feature of cosmopolitanism, it seems reasonable that one of cosmopolitanism's theoretical backdrops be relational work, particularly politeness theory. It is important to point out with Brown and Levinson (1987) that politeness allows communication to take place between potentially aggressive partners, which make politeness theory relevant in the realm of cosmopolitan theory. In Kant's (2007) view mentioned previously in the paper, not only individuals but also nations states are, by default, potentially aggressive partners.

The notions of politic and (im)polite behavior along the lines proposed by Richard Watts, a key figure in politeness theory, are as follows:

[L]inguistic behaviour which is perceived to be appropriate to the social constraints of the ongoing interaction, i.e. as non-salient, should be called politic behaviour. ... Linguistic behaviour which is perceived to be beyond what is expectable, i.e. salient behaviour, should be called polite or impolite depending on whether the behaviour itself tends towards the negative or positive end of the spectrum of politeness (Watts 2003, p. 19).

Rather than restricting these notions to linguistic behaviour, we can attempt to apply them to behaviour in general. For instance, the actions of Hellenistic cosmopolites could be considered as cosmoimpolite. Laërtius (1853, p.233) tells us that Diogenes of Sinope pointed at people with his middle finger. He is also said to have defecated in the theatre, urinated on some people who insulted him, dropped by at people's houses unannounced to offer them advice, strolled the streets in full daylight with a lamp saying that he was just looking for an honest man, etc. Like dogs, the Dog Philosophers ate and made love in public, went barefoot, and slept in tubs and at crossroads. What makes their actions cosmoimpolite is not the fact that they violated what was considered socially appropriate behaviour because, as previously established, defacing the currency is one key underlying principle of cosmopolitanism. 
Rather, the fact that this defacing led to conflict, thus disrupting their peaceful co-existence in their communities.

Cosmopolitic could perhaps characterize the perspective of the dominant capitalist bourgeoisie whose global reach and its modes of production were bound to equalize the differences between nations as described by Marx and Engels in The Communist Manifesto written fifty-three years after Kant's Perpetual Peace. Moreover, it might be used to describe what Frantz Fanon called a 'profoundly cosmopolitan mould' (Fanon 1961, p. 149) in The Wretched of the Earth. According to Fanon, this formerly colonized bourgeoisie was dominated by capitalist interests. Moreover, these puppets and imitators of the colonizers, while intent on keeping the peace, tended towards mediocrity as they lacked the spirit of initiative. They, therefore, did not deface but endorse the currency.

Cosmopolite, on the other hand, could be used to imply a harmonious defacement of the currency. The actions of Immanuel Kant might, for instance, provide an illustration. Kant, a visionary with dreams global in size, in the midst of a heavily war-torn Europe, wrote for a peaceful coexistence of human beings. He reinvented cosmopolitanism, thus defacing its currency. He took a revolutionary stance but in a peaceful manner by politely flattering the statesmen whom he obviously depended on to carry out his work. He referred to politicians as ‘world-wise statesmen' and to his own thoughts as 'empty ideas' (Kant 2007, p. 5). He practised the peace he preached and seemed willing to accommodate others (the 'world-wise statesmen') who did not necessarily subscribe to his cosmopolitan vision.

Cosmopoliteness can, therefore, serve as an umbrella term encompassing cosmopolitic and cosmo(im)polite behaviour. Such a model is not meant for sorting cosmopolitans into different types or for branding behaviour, rather for the purpose of facilitating useful reflection so as to spark a debate leading to a deeper understanding.

\section{Conclusion}

In the same way that Cynicism became the popular philosophy of antiquity as it was no longer reserved for a social or intellectual elite and everyone could philosophize, cosmopolitanism, too, is on its way to become the popular philosophy of our time. As Kant's 'empty ideas' fill up with actions, so does the cosmopolitan glass. We are faced with a plethora of definitions of cosmopolitanism. While these definitions should by no means be received uncritically, they should also not be viewed as interfering with cosmopolitanism's 
process of becoming, rather as assisting that process.

The cosmopolitan approach to cosmopolitanism proposed here involves filling the glass with both: sameness and difference, the general and the particular, genus and differentia, respectively. In order to establish some sort of general blueprint for cosmopolitanism, a functional approach is taken in that the main question is not what, rather why, cosmopolitanism is. Its trajectory starting off with the Cynics and the Stoics via Immanuel Kant to the present suggests that cosmopolitanism serves as a conceptual tool for defacing the currency. This genus is mixed and shaken together with the differentia, i.e. the conceptualization of cosmopolitanism as a kind of performative practice through which branding can be dodged.

This paper did not set out to toss a definition of cosmopolitanism at the reader right from the start, rather to stir the imagination and prompt one to concoct one's own working definition post-analysis so as to facilitate a conceptualization of cosmopolitanism as a performative practice. How do people, cultures, countries, the world - how do I - do cosmopolitanism? Perhaps one day the pipe dream(s) of the cosmopolitan project(s) will become reality and will not only stand the test of time but also have in store great rewards for humanity. Until then, we should not be arguing if the cosmopolitan glass is half empty or half full but rather ask ourselves what we can do with what is in the glass. Bottoms up!

\section{References}

Bateman, R. 2008, 'Robert Bateman Get to Know Program', thegreenpages.ca [Website], viewed 11 October $2011<$ http://thegreenpages.ca/ca/2008/06/12/robert_bateman_get_to_know_pro/>.

Beck, U. 2002, 'The Cosmopolitan Society and Its Enemies', Theory Culture Society, vol. 19, no. 1, pp. 17-44.

Bentham, J. 2007, An Introduction to the Principles of Morals and Legislation, Forgotten Books.

Branham, R. \& Goulet-Cazé, M. 1996, 'Introduction', The Cynics: The Cynic Movement in Antiquity and Its Legacy, University of California Press, Berkeley, pp. 1-27.

Brown, C. 1992, International Relations Theory: New Normative Approaches, Harvester Weatsheaf, Hempel Hempstead.

Brown, P. \& Levinson, C. 1987, Politeness: Some Universals in Language Usage, Cambridge University Press, Cambridge.

Cauti, C. (Ed.) 2003, Oscar Wilde: The Picture of Dorian Gray, Barnes \& Noble Classics, New York.

Cecchini, T. 2004, A Bartender's Life in New York, Broadway Books, New York.

— . 2008, 'Best Cosmopolitans in Sydney', au.timeout.com [Website], viewed 11 October $2011<$ http://www.au.timeout.com/sydney/bars/features/2275/best-cosmopolitans-insydney>.

Cohen, D. 1991, Law, Sexuality and Society: The Enforcement of Morals in Classical Athens, 
Cambridge University Press, Cambridge.

Collingwood, R. 2005, An Essay on Philosophical Method. Introd. and additional material James Connelly and Giuseppina D’Oro, Oxford University Press, New York.

Delanty, G. 2008, 'The Cosmopolitan Imagination', Revista CIDOB d'Afers Internacionals, vol. 82, no. 83, pp. 217-230.

—. 2006, 'The Cosmopolitan Imagination: Critical Cosmopolitanism and Social Theory', The British Journal of Sociology, vol. 57, no. 1, pp. 25-47.

Edel, A. 1996, Aristotle and His Philosophy, Transaction Publishers, New Jersey.

Epictetus IX, 2011, 'The Golden Sayings of Epictetus IX', Ancient History at About.com [Website], viewed 11 October $2011<$ http://ancienthistory.about.com/library/bl/bl_text_epictetus.htm >.

Frantz, F. 1961, The Wretched of the Earth, Grove Press, New York.

Hobbes, T. 2008, Leviathan, Forgotten BookHochschild, J. 1984, The New American

Dilemma: Liberal Democracy and School Desegregation, Yale, New Haven.

Kant, I. 1963, 'Idea for a Universal History from a Cosmopolitan Point of View', in Lewis White Beck (Trans.) On History, The Bobbs-Merrill Co., Indianapolis.

_. 2007, Perpetual Peace, Filiquarian Publishing, Minneapolis.

Kataras, C. 2008, Nice Capitalism: A Secret Journey to the Death of the Arrogant Brand, Xlibris, United States.

Kleingeld, P. 1999, 'Six Varieties of Cosmopolitanism in Late Eighteenth-Century Germany', Journal of the History of Ideas, vol. 60, no. 3, pp. 505-524.

Laërtius, D. 1853, The Lives and Opinions of Eminent Philosophers, Charles Duke Yonge (Trans.) Henry G. Bohn, London.

Lévinas, E. 1991, Totality and Infinity: An Essay on Exteriority, Kluwer Academic Publishers, The Netherlands.

Marx, K. \& Engels, F. 2009, The Communist Manifesto, The Echo Library, Middlesex.

Mieder, W. 2009, Yes We Can: Barack Obama's Proverbial Rhetoric, Peter Lang, New York.

Mouffe, C. 2000, The Democratic Paradox, Verso, New York.

Navia, L. 1996, Classical Cynicism: A Critical Study, Greenwood Publishing Group, Westport.

Nussbaum, M. 1994, 'Patriotism and Cosmopolitanism', The Boston Review, vol. 19, no. 5, pp. 1-8.

Pollock, S., Bhabha, H., Breckenridge, C. \& Chakrabarty, D. 2000, 'Cosmopolitanisms', Public Culture, vol. 12, no. 3, pp. 577-589.

Poulsen, F. 2008, Element of an Archaeology of Cosmopolitanism in Western Political Thought: A Return to the French Enlightenment, Department of Political Science, Copenhagen, 2008.

Smith, A. 1991, National Identity, University of Nevada, Reno.

—. 2004, The Antiquity of Nations, Polity, Malden.

— . 2005, 'When is the Nation? Towards an Understanding of Theories of Nationalism', in Atsuko Ichijo and Gordana Uzelac (Eds.) The Genealogy of Nations: An Ethno-Symbolic Approach, Routledge, New York, pp. 94-112.

Stade, R. 2007, Cosmos and Polis, Past and Present, Malmö University, Sweden.

Vertovec, S. \& Cohen, R. (Eds.) 2002, Conceiving Cosmopolitanism: Theory, Context, and Practice, Oxford University Press, Oxford.

Watts, R. 2003, Politeness, Cambridge University Press, Cambridge.

Werbner, P. 2008, 'Cosmopolitanism, Globalisation and Diaspora: Stuart Hall in Conversation with Pnina Werbner', Anthropology and the New Cosmopolitanism, Palgrave Macmillan, Gordonsville, pp. 345-360. 